\title{
SUSCEPTIBILIDAD AL DESLIZAMIENTO EN EL CORREDOR SIQUIRRES-TURRIALBA
}

\author{
LANDSLIDE SUSCEPTIBILITY IN THE SIQUIRRES-TURRIALBA CORRIDOR
}

\author{
Gustavo Segura $^{1 *}$, Elena Badilla ${ }^{2,3}$, Luis Obando ${ }^{2,3}$ \\ ${ }^{1}$ Refinadora Costarricense de Petróleo \\ ${ }^{2}$ Escuela Centroamericana de Geología, Apdo. 214-2060, Universidad de Costa Rica \\ ${ }^{3}$ Centro de Investigaciones en Ciencias Geológicas, Universidad de Costa Rica \\ *Autor para contacto: gasegurac@gmail.com
}

(Recibido: 24/11/2010; aceptado: 28/11/2011)

\begin{abstract}
A landslide suceptibility zonation was performed in a $10 \mathrm{~km}$ wide corridor along the RECOPE pipeline between the cites of Siquirres and Turrialba. The total study area is $330 \mathrm{~km}^{2}$.

Analysis was based on aerial photointerpretation, bibliographic research and the application of the Mora-Vahrson method (Mora et al., 1992), in which slope was used instead of the internal relief parameter. A landslide inventory map was included in the evaluation of the lithological suceptibility parameter.

Zonation resulted in a predominance of areas with low landslide susceptibility $(33,9 \%)$, mostly located where Tuis Formation is present, south east of the study area, followed by Suretka Formation and partially Andesitas Poás.

Keywords: susceptibility, landslides, pipeline, Siquirres, Turrialba, RECOPE, Mora-Vahrson.

RESUMEN: Se presenta una zonificación de la susceptibilidad al deslizamiento en el sector entre las localidades de Siquirres y Turrialba, específicamente para un corredor de $10 \mathrm{~km}$ de ancho sobre la ruta del poliducto de RECOPE, que cubre una extensión aproximada de $330 \mathrm{~km}^{2}$.

El estudio se realizó a partir de la interpretación de fotografías aéreas, información bibliográfica y la aplicación del método Mora \& Vahrson (Mora et al., 1992), sustituyendo el relieve relativo por un mapa de pendientes e incorporando un mapa inventario de deslizamientos en la evaluación del parámetro de susceptibilidad litológica.

Como resultado de la zonificación, se obtuvo que las áreas correspondientes a susceptibilidad baja abarcan la mayor parte del mapa (33,9\%) y se presentan mayormente en sectores donde afloran las unidades litoestratigráficas Tuis, al sureste del área, Suretka y en algunos sectores de la formación Andesitas Poás. Las áreas correspondientes a susceptibilidad media $(25,3 \%)$ se presentan principalmente en rocas de las formaciones Andesitas Poás, Uscari y Guayacán; mientras que las áreas correspondientes a susceptibilidad alta $(13,4 \%)$ se presentan principalmente en sectores donde afloran las rocas de las formaciones Andesitas Poás, Uscari, Brechas La Unión y Río Banano.

Palabras clave: susceptibilidad, deslizamientos, poliducto, Siquirres, Turrialba, RECOPE, Mora-Vahrson
\end{abstract}

SEGURA, G., BADILLA, E. \& OBANDO, L. 2011: Susceptibilidad al deslizamiento en el corredor Siquirres-Turrialba.- Rev. Geol. Amér. Central, 45: 101-121. 


\section{INTRODUCCIÓN}

Este trabajo tiene como finalidad realizar la zonificación de la susceptibilidad al deslizamiento, en el área definida por un corredor de $10 \mathrm{~km}$ de ancho a lo largo de la ruta del poliducto de la Refinadora Costarricense de Petróleo (RECOPE), entre Siquirres y Turrialba, utilizando indicadores morfodinámicos. Para ello, se determinará la susceptibilidad al deslizamiento mediante la evaluación y combinación de factores de susceptibilidad y de disparo, resultado que será posteriormente comparado con un mapa inventario de deslizamientos, con el fin de determinar su grado de certeza.

\section{Ubicación geográfica de la zona de estudio}

El área de estudio se ubica entre las ciudades de Siquirres y Turrialba, entre las coordenadas Lambert Costa Rica Norte 207 000-233 000 N y $567000-592000 \mathrm{E}$, específicamente dentro de un corredor de $10 \mathrm{~km}$ de ancho a lo largo de la ruta del poliducto de RECOPE, que cubre una extensión aproximada de $330 \mathrm{~km}^{2}$ (Fig. 1). Forma parte de las hojas topográficas Bonilla (IGN, 1967) y Tucurrique (IGN, 1981), escala 1:50 000.

\section{Antecedentes}

La determinación de áreas propensas a deslizamientos en la zona de estudio ha sido llevada a cabo tanto por la Unidad SIGRECOPE y profesionales de la Gerencia de Distribución y Mercadeo de RECOPE, así como por Chavarría (1996), Pérez (1996), Rojas (1996) y Sibaja (1996).

Los estudios llevados a cabo por los geólogos de RECOPE, analizaron aspectos específicos sobre la problemática presentada en lugares que presentan deslizamientos importantes (G. Bottazzi, comunicación escrita, 2007). Algunos de estos son 52 Millas, Santa Marta, el área entre Peralta y Linda Vista y Alto de Guayacán. La problemática presentada en estos sitios se relaciona con la inestabilidad de los taludes, deslizamientos y su influencia en los cauces fluviales que afectan directamente el poliducto.
Las investigaciones realizadas por Chavarría (1996), Pérez (1996), Rojas (1996) y Sibaja (1996), incluyeron la identificación y el mapeo de los deslizamientos que afectan al poliducto de RECOPE, dentro del área comprendida entre Turrialba y Siquirres.

\section{METODOLOGÍA}

Existen diferentes metodologías para la zonificación de la susceptibilidad a deslizamientos. Entre ellas están el método heurístico y el estadístico.

a) De acuerdo con van Westen \& Soeters (2000), en el método heurístico el criterio experto del geomorfólogo que realiza el estudio se utiliza para clasificar la susceptibilidad. La cartografía de los movimientos en masa y su contexto geomorfológico son el principal elemento de entrada para la determinación de la amenaza. Dos tipos de análisis heurístico pueden distinguirse: el análisis geomorfológico y la combinación cualitativa de mapas.

- En el análisis geomorfológico, conocido también como el método de cartografía directa, el grado de susceptibilidad del terreno es determinado por el geólogo directamente en el campo. El proceso se basa en su experiencia. Los criterios aplicados son, por lo tanto, difíciles de definir, ya que varían según el sitio estudiado.

- Por el contrario, la combinación cualitativa de mapas busca superar el problema de los "criterios ocultos" del análisis geomorfológico. En este método, el geocientífico usa su criterio experto para asignar pesos (valores que representan un determinado grado de importancia) a una serie de mapas parámetro (mapas de condiciones del terreno que se consideran relacionadas, en diferente grado, con la ocurrencia de deslizamientos). Las condiciones del terreno se suman de acuerdo con estos pesos, lo que lleva a valores de susceptibilidad que pueden ser agrupados en categorías o clases. Este método ha adquirido bastante popularidad para la zonificación de inestabilidad de laderas. Su problema es que la asignación exacta de pesos a los diversos mapas parámetro se basa en ocasiones en un 


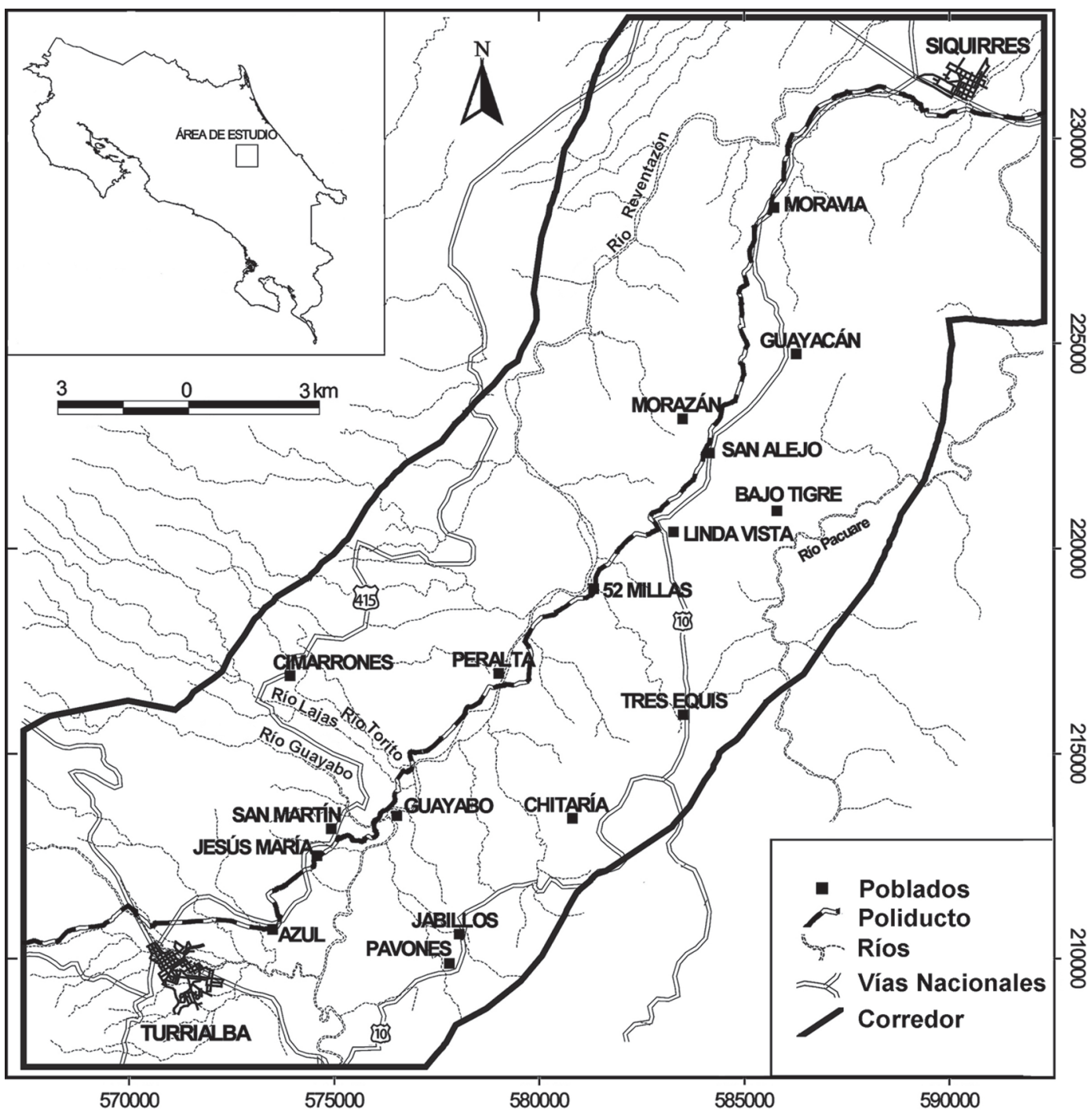

Fig. 1: Ubicación geográfica del área de estudio

insuficiente conocimiento de campo de los factores cruciales, lo que lleva a generalizaciones inaceptables (van Westen \& Soeters, 2000). Este tipo de enfoque heurístico se basa en el conocimiento a priori de las causas de deslizamiento en el área investigada; de ahí que los factores de inestabilidad sean clasificados y sus pesos asignados, de acuerdo a su importancia asumida o esperada en la generación de deslizamientos. Su confiabilidad es directamente dependiente de qué tanto y qué tan bien el investigador conozca los procesos geomorfológicos que actúan en el terreno (Carrara et al., 1995).

b) El enfoque estadístico se basa en la relación observada entre cada factor y la distribución de deslizamientos pasada y presente. Así, la evaluación de la susceptibilidad de deslizamiento puede volverse tan objetiva como sea posible, por el hecho de que los factores de inestabilidad y sus interrelaciones son evaluados con base en estadística. La fortaleza de este enfoque depende directamente de la calidad y cantidad de datos 
recolectados. Errores en la cartografía de deslizamientos pasados y presentes ejercerán una gran y difícilmente predecible influencia en el modelo. Como el método es regido por los datos, el modelo construido para una región no es fácilmente extrapolable a áreas vecinas (Carrara et al., 1995).

En lo que respecta a la presente investigación, la metodología para realizar la zonificación de la susceptibilidad a deslizamientos en el área de estudio puede considerarse como un híbrido entre un método heurístico y uno estadístico; se dividió esencialmente en tres fases: i) el inventario de deslizamientos, ii) la aplicación del modelo heurístico conocido como Mora-Vahrson (Mora et al., 1992), con algunas modificaciones, y iii) la evaluación de la metodología utilizada.

\section{i) Inventario de deslizamientos}

El mapa inventario de deslizamientos se creó a partir del análisis fotogeológico del área de estudio, utilizando las fotografías aéreas del Proyecto Carta 2005.

Como información base, se contó con los deslizamientos identificados y cartografiados por Sáenz (1985), Fernández (1987), Barboza \& Fernández (1987), Perazzo et al. (1994), Chavarría (1996), Pérez (1996), Rojas (1996), Sibaja (1996) y Peraldo \& Rojas (1998). Esta información se utilizó como guía para el reconocimiento e identificación de zonas susceptibles a presentar deslizamientos, para posteriormente realizar un análisis más detallado por medio de las fotografías aéreas.

\section{ii) El método Mora-Vahrson}

El método Mora-Vahrson (Mora et al., 1992) es de tipo heurístico, específicamente una combinación cualitativa de mapas. Se aplica mediante la combinación de varios factores y parámetros, los cuales se obtienen de la observación y medición de indicadores morfodinámicos y su distribución espacio-temporal. La combinación de los factores y parámetros se realiza considerando que los deslizamientos ocurren cuando en una ladera, compuesta por una litología determinada, con cierto grado de humedad y con cierta pendiente, se alcanza un grado de susceptibilidad (elementos pasivos). Bajo estas condiciones, los factores externos y dinámicos, como son la sismicidad y las lluvias intensas (elementos activos), actúan como factores de disparo que perturban el equilibrio, la mayoría de las veces precario, que se mantiene en la ladera.

Es así como se considera que el grado de amenaza al deslizamiento es el producto de los elementos pasivos y de la acción de los factores de disparo (Mora et al., 1992), de acuerdo con la siguiente fórmula:

$$
\mathrm{H}=\left(\mathrm{S}_{\mathrm{L}} * \mathrm{~S}_{\mathrm{H}} * \mathrm{~S}_{\mathrm{R}}\right) *\left(\mathrm{D}_{\mathrm{LL}}+\mathrm{D}_{\mathrm{S}}\right)(1)
$$

Donde:

$\mathrm{S}_{\mathrm{L}}$ : valor del parámetro de susceptibilidad litológica,

$\mathrm{S}_{\mathrm{H}}$ : valor del parámetro de humedad del terreno,

$\mathrm{S}_{\mathrm{R}}$ : valor del parámetro del relieve gico y

$\mathrm{D}_{\mathrm{S}}$ : valor del parámetro de disparo sismoló-

$\mathrm{D}_{\mathrm{LL}}$ : valor del parámetro de disparo por lluvia

Las modificaciones introducidas en esta investigación, a la aplicación de la metodología Mora-Vahrson (Mora et al., 1992) para la determinación de la susceptibilidad al deslizamiento, son las siguientes:

1) Creación de un mapa de pendientes (parámetro P) en sustitución del índice de relieve relativo (parámetro del relieve SR se sustituye por parámetro de la pendiente $\mathrm{SP}$ ). Esta modificación se realizó con base en el modelo planteado por Mora et al. (2002) y que se conoce como método MoraVahrson-Mora (MVM). Esta metodología propone una clasificación más simplificada del grado de amenaza, denominándola "Susceptibilidad al Deslizamiento".

2) Valoración del parámetro de susceptibilidad litológica (SL), mediante un enfoque de tipo estadístico (van Westen \& Soeters, 2000), basado en el mapa inventario de deslizamientos obtenido a partir de fotografías aéreas. Con base en la intersección de las capas de litología y de deslizamientos, 
se obtuvo el valor de área por litología afectada por deslizamientos, con respecto a la extensión total de cada formación, es decir, densidad de deslizamientos por unidad litológica, valor que se relaciona luego con la densidad total de deslizamientos en el área de estudio.

El resultado se presenta en un mapa que muestra la zonificación de la susceptibilidad al deslizamiento. Estas áreas se clasifican cuantitativamente con valores relativos que corresponden a diferentes grados de susceptibilidad. Muestran condiciones de amenaza relativa, al comparar áreas adyacentes unas con otras y no la amenaza absoluta.

El cálculo de los factores morfodinámicos incluye:

- Elaboración de un mapa de pendientes a partir de un modelo digital de elevación (MED), creado a su vez a partir de curvas de nivel cada $10 \mathrm{~m}$ y auxiliares cada $5 \mathrm{~m}$, estableciendo una rejilla cuadriculada de $10 \times 10 \mathrm{~m}$. Se definió un corredor de $10 \mathrm{~km}$ de ancho sobre la ruta del poliducto entre Siquirres y Turrialba que abarca un área de $330 \mathrm{~km}^{2}$, en donde se concentró el análisis de la susceptibilidad al deslizamiento (Fig.1). La información fuente es la cartografía a escala 1:25 000, del convenio MINAE-RECOPE de 1998.

- Creación de la capa de geología a partir del mapa geológico de la Hoja Tucurrique de Fernández (1987), del mapa geológico del área norte de la cuenca de Limón Sur (hoja topográfica Bonilla) de la División de Recursos Petrolíferos de la Gerencia de Producción Primaria de RECOPE (Barboza \& Fernández, 1987), así como de los mapas geológicos de Chavarría (1996), Pérez (1996), Rojas (1996) y Sibaja (1996). Para esto se realizó la digitalización y georreferenciación de los mapas fuente y se trazaron los límites formacionales, para integrar la información geológica y obtener el mapa geológico correspondiente. $\mathrm{La}$ adaptación de las escalas de los mapas y la unión de las áreas se realizó con base en la topografía a escala 1:25000 y de elementos geográficos tales como poblados, ríos, vías, entre otros. La nomenclatura de las unidades geológicas se basó en las terminología utilizada por Linkimer \& Aguilar
(2000), Fernández (1987), Chavarría (1996), Pérez (1996), Rojas (1996) y Sibaja (1996).

- Evaluación del parámetro de humedad del suelo $\left(\mathrm{S}_{\mathrm{H}}\right)$, a partir de los datos de precipitación promedio mensual registrados en las estaciones meteorológicas El Sauce, Pacuar, Siquirres y La Amistad, del Instituto Costarricense de Electricidad (ICE), así como la estación Guayabo, del Instituto Meteorológico Nacional (IMN). La longitud del registro en las estaciones del ICE es de 30 años, mientras que la de la estación Guayabo, del IMN, es de 20. Estos promedios mensuales se valoran de acuerdo con la clasificación propuesta en el modelo Mora \& Vahrson (Mora et al., 1992).

- Evaluación del parámetro de disparo por lluvias $\left(D_{L L}\right)$, a partir de la serie de valores máximos diarios anuales registrados en las estaciones meteorológicas anteriormente citadas. La valoración de este parámetro se realizó mediante el cálculo de la precipitación máxima para un período de retorno de 100 años, mediante el método Gumbel (Linsley et al., 1977).

- Evaluación del factor de disparo por sismos $\left(D_{S}\right)$ : para el cálculo de este factor se utilizaron los mapas de intensidades sísmicas (Mercalli Modificada, MM) de eventos sísmicos que han afectado la zona de estudio en los últimos 100 años, según Rojas (1991), Barquero \& Peraldo (1993) y Barquero \& Rojas (1994).

El mapa de zonificación de la susceptibilidad al deslizamiento se obtuvo mediante la valoración de los parámetros involucrados y la aplicación de la ecuación 1.

La metodología no incluye geotecnia descriptiva de los deslizamientos. No se tomaron muestras ni se realizaron análisis de laboratorio. Esta investigación constituye un estudio cualitativo de la susceptibilidad al deslizamiento; determina áreas potencialmente inestables, sin considerar aspectos temporales de ocurrencia de los fenómenos. La finalidad de esta metodología es definir posibles áreas críticas, que posteriormente puedan ser sometidas a análisis detallados (Mora et al., 1992).

Como parte de esta investigación, se realizaron giras de campo con el objetivo de verificar las principales áreas de los deslizamientos que fueron definidos por medio de las fotografías aéreas. 


\section{iii) Evaluación de la metodología utilizada}

La evaluación del método utilizado se basó principalmente en la determinación del grado de coincidencia entre las áreas de deslizamientos y las áreas para cada clase de susceptibilidad. Esto se realizó con base en la información obtenida a partir de la intersección (sobreposición espacial de capas ráster en un Sistema de Información Geográfica, mediante operador lógico AND) de las capas de inventario de deslizamientos y de susceptibilidad al deslizamiento. De esta manera, se determinó qué porcentaje de los deslizamientos inventariados coincide con cada uno de los grados de susceptibilidad, con lo que se puede estimar el grado de confiabilidad de la zonificación obtenida, además de detectar zonas donde la zonificación no coincide con la realidad observada, lo que permite hacer cuestionamientos al método.

\section{MAPA INVENTARIO DE DESLIZAMIENTOS}

Se realizó mediante fotointerpretación, utilizando las fotografías aéreas del Proyecto Carta 2005 , con una resolución de 2 metros. La recopilación de deslizamientos a partir de trabajos anteriores en la zona de estudio, se utilizó para un reconocimiento preliminar del área. Sin embargo, el uso de las fotografías aéreas permitió redefinir los límites de las áreas deslizadas cartografiadas en estas investigaciones. El mapa resultante no solo incluye estas áreas, sino que define una serie de macrodeslizamientos presentes en el área de estudio.

En la figura 2 se presenta la distribución geográfica de los deslizamientos y escarpes de erosión fluvial, determinados a partir de las fotografías aéreas y comprobación de campo. Comprenden un área de $147 \mathrm{~km}^{2}$ de los $330 \mathrm{~km}^{2}$ que conforman el área de estudio (corredor de $10 \mathrm{~km}$ ), representando un 44,6\% del área total. En el cuadro 1 se presenta una lista de los deslizamientos y escarpes de erosión fluvial definidos, codificados de acuerdo a la figura 2, con sus respectivas características geométricas. El volumen de material removido fue determinado con base en la siguiente relación matemática (Varnes, 1978):
Volumen $=($ largo máximo $)$ x (ancho máximo) $\mathrm{x}$ (profundidad promedio) $\mathrm{x}(\pi / 6)$

Donde $\pi$ equivale a 3,14 .

Debido a la naturaleza de esta investigación, el inventario de deslizamientos incluye deslizamientos antiguos y activos; sin embargo, el grado de actividad para cada uno de los deslizamientos en particular no fue definido.

Peraldo \& Rojas (1998) identificaron 240 deslizamientos de diferente tamaño entre Turrialba y La Junta, y señalan que algunos de ellos se reactivaron a principios del siglo pasado; tal es el caso de las áreas de inestabilidad Piedras de Fuego, Palo Alto, Encanto, Bonilla y Chiz. Actualmente, los deslizamientos Lagunas Lankaster (código 64), 52 Millas (código 59), Pilón de Azúcar-Tres Equis (código 66), Cimarrones (código 68), Jesús María (código 39) y Quebrada Piedra Grande (código 41) (Fig. 2 y cuadro 1), muestran actividad comprobada, ya que continuamente presentan problemas de inestabilidad.

\section{DETERMINACIÓN DE LA SUSCEPTIBILIDAD AL DESLIZAMIENTO}

Como se indicó anteriormente, la zonificación de la susceptibilidad al deslizamiento se realizó utilizando indicadores morfodinámicos, de acuerdo a lo establecido en el método MoraVahrson (Mora et al., 1992). Los resultados se presentan en un mapa que muestra áreas con diferentes grados de susceptibilidad al deslizamiento.

\section{Evaluación de factores}

La evaluación de los factores se realizó mediante la asignación de pesos relativos, de acuerdo con su grado de influencia en la susceptibilidad al deslizamiento. Comprendió la preparación de mapas temáticos o capas de información en formato ráster, para cada uno de ellos. A continuación se describe el procedimiento de evaluación de los factores involucrados en el análisis, a saber el parámetro de la pendiente $\left(\mathrm{S}_{\mathrm{P}}\right)$, de susceptibilidad litológica $\left(\mathrm{S}_{\mathrm{L}}\right)$, de humedad del terreno $\left(\mathrm{S}_{\mathrm{H}}\right)$, disparo sismológico (DS) y disparo por lluvias $\left(\mathrm{D}_{\mathrm{LL}}\right)$, 
Cuadro 1

Inventario de deslizamientos y escarpes de erosión fluvial, determinados a partir de fotografías aéreas y observaciones de campo (Fig.2)

\begin{tabular}{|c|c|c|c|c|}
\hline Código & $\begin{array}{c}\text { Deslizamiento/escarpe de } \\
\text { erosión }\end{array}$ & Nombre & Área $\left(\mathrm{m}^{2}\right)$ & Volumen $\left(\mathrm{m}^{3}\right)$ \\
\hline 1 & $\begin{array}{c}\text { Escarpe de erosión } \\
\text { fluvial }\end{array}$ & Bonilla Abajo & 36062 & 79082 \\
\hline 2 & $\begin{array}{c}\text { Escarpe de erosión } \\
\text { fluvial }\end{array}$ & Bonilla Abajo & 42867 & 310782 \\
\hline 3 & Deslizamiento & Eslabón & 57975 & 143576 \\
\hline 4 & $\begin{array}{c}\text { Escarpe de erosión } \\
\text { fluvial }\end{array}$ & Río Reventazón & 108020 & 933842 \\
\hline 5 & Deslizamiento & Río Siquirres & 115571 & 296583 \\
\hline 6 & Deslizamiento & Quebrada Borrachos & 169696 & 716815 \\
\hline 7 & Deslizamiento & Bóveda-Eslabón & 170173 & 1317631 \\
\hline 8 & Deslizamiento & Río Chitaría & 245651 & 1775269 \\
\hline 9 & Deslizamiento & Florida & 250121 & 1286973 \\
\hline 10 & Deslizamiento & Río Izarco & 252910 & 922741 \\
\hline 11 & Deslizamiento & Río Siquirres & 277730 & 1411857 \\
\hline 12 & Deslizamiento & Río Bonilla & 356714 & 3674997 \\
\hline 13 & Deslizamiento & Río Siquirritos & 395443 & 1893137 \\
\hline 14 & $\begin{array}{l}\text { Escarpe de erosión } \\
\text { fluvial }\end{array}$ & Río Reventazón & 414365 & 2283440 \\
\hline 15 & $\begin{array}{l}\text { Escarpe de erosión } \\
\text { fluvial }\end{array}$ & Río Reventazón & 414591 & 2234245 \\
\hline 16 & Deslizamiento & Codo del Diablo & 422470 & 2497854 \\
\hline 17 & Deslizamiento & Bóveda-Eslabón & 464774 & 4081273 \\
\hline 18 & Deslizamiento & Fila Mirador & 481398 & 1598731 \\
\hline 19 & Deslizamiento & Río Colima & 489931 & 3131710 \\
\hline 20 & Deslizamiento & Quebrada Borrachos & 492907 & 2750489 \\
\hline 21 & Deslizamiento & Alto Varal & 501938 & 2870065 \\
\hline 22 & Deslizamiento & Quebrada Bóveda & 535690 & 4344739 \\
\hline 23 & Deslizamiento & Río Turrialba & 560831 & 2048300 \\
\hline 24 & $\begin{array}{l}\text { Escarpe de erosión } \\
\text { fluvial }\end{array}$ & Río Bonilla & 601056 & 5101646 \\
\hline 25 & Deslizamiento & Codo del Diablo & 627296 & 1578967 \\
\hline 26 & Deslizamiento & Quebrada Ganga & 700358 & 4115139 \\
\hline 27 & $\begin{array}{l}\text { Escarpe de erosión } \\
\text { fluvial }\end{array}$ & Río Bonilla & 707936 & 24195935 \\
\hline 28 & Deslizamiento & Fila Mirador & 788896 & 3187986 \\
\hline 29 & Deslizamiento & Cerro Encanto & 800555 & 7389673 \\
\hline 30 & $\begin{array}{l}\text { Escarpe de erosión } \\
\text { fluvial }\end{array}$ & Río Bonilla & 801557 & 11281290 \\
\hline 31 & Deslizamiento & Quebrada Terciopelo & 940023 & 5182472 \\
\hline
\end{tabular}


Cuadro 1 (continuación)

\begin{tabular}{|c|c|c|c|c|}
\hline Código & $\begin{array}{c}\text { Deslizamiento/escarpe de } \\
\text { erosión }\end{array}$ & Nombre & Área $\left(\mathrm{m}^{2}\right)$ & Volumen $\left(\mathrm{m}^{3}\right)$ \\
\hline 32 & $\begin{array}{l}\text { Escarpe de erosión } \\
\text { fluvial }\end{array}$ & Río Reventazón & 956179 & 5679977 \\
\hline 33 & $\begin{array}{l}\text { Escarpe de erosión } \\
\text { fluvial }\end{array}$ & Río Reventazón & 959649 & 12203396 \\
\hline 34 & Deslizamiento & Sitio de Mata & 1210529 & 24143912 \\
\hline 35 & Deslizamiento & Río Guayabo & 1308741 & 10127363 \\
\hline 36 & Deslizamiento & Animas & 1364123 & 8972007 \\
\hline 37 & Deslizamiento & $\begin{array}{c}\text { Desembocadura Río } \\
\text { Guayabo }\end{array}$ & 1374796 & 5993676 \\
\hline 38 & Deslizamiento & Quebrada Linda & 1463682 & 10811688 \\
\hline 39 & Deslizamiento & Jesús María & 1583792 & 9848454 \\
\hline 40 & Deslizamiento & Guayacán & 1696251 & 13212508 \\
\hline 41 & Deslizamiento & $\begin{array}{c}\text { Quebrada Piedra } \\
\text { Grande }\end{array}$ & 2093758 & 33493771 \\
\hline 42 & Deslizamiento & Río Bonilla & 2097917 & 27158411 \\
\hline 43 & Deslizamiento & Pascua & 2383161 & 25625970 \\
\hline 44 & Deslizamiento & Quebrada Danta & 2391104 & 17601072 \\
\hline 45 & Deslizamiento & Quebrada Lajas & 2440821 & 22396205 \\
\hline 46 & Deslizamiento & Quebrada Huacas & 2478040 & 22166720 \\
\hline 47 & Deslizamiento & Río Azul & 2517286 & 23710338 \\
\hline 48 & Deslizamiento & Quebrada Huacas & 2632588 & 35558804 \\
\hline 49 & Deslizamiento & $\begin{array}{l}\text { Quebrada Pavones- } \\
\text { Torito }\end{array}$ & 2643042 & 23572398 \\
\hline 50 & Deslizamiento & Río Guayabo & 2831632 & 42237297 \\
\hline 51 & Deslizamiento & Quebrada Sartén & 2841816 & 13950728 \\
\hline 52 & Deslizamiento & Quebrada Tigre & 2842122 & 21734610 \\
\hline 53 & Deslizamiento & Río Aquiares & 3075440 & 23276541 \\
\hline 54 & Deslizamiento & Lomas & 3089892 & 22408170 \\
\hline 55 & Deslizamiento & Quebrada Guayacán & 3365864 & 38330295 \\
\hline 56 & Deslizamiento & Río Izarquito & 3480477 & 50302653 \\
\hline 57 & Deslizamiento & Río Siquirres & 3778641 & 33341614 \\
\hline 58 & Deslizamiento & Quebrada Terciopelo & 4259734 & 34108955 \\
\hline 59 & Deslizamiento & 52 Millas & 4468330 & 24630474 \\
\hline 60 & Deslizamiento & Río Izarco & 4857114 & 52586758 \\
\hline 61 & Deslizamiento & Quebrada Lajas & 5177701 & 44827349 \\
\hline 62 & Deslizamiento & Quebrada Quebradón & 5474277 & 68612742 \\
\hline 63 & Deslizamiento & Petróleo & 5613588 & 62160879 \\
\hline 64 & Deslizamiento & Lagunas Lankaster & 7116914 & 48246682 \\
\hline
\end{tabular}


Cuadro 1 (continuación)

\begin{tabular}{ccccc}
\hline Código & $\begin{array}{c}\text { Deslizamiento/escarpe de } \\
\text { erosión }\end{array}$ & Nombre & Área $\left(\mathrm{m}^{2}\right)$ & Volumen $\left(\mathrm{m}^{3}\right)$ \\
\hline 65 & Deslizamiento & Linda Vista & 7670626 & 44311680 \\
66 & Deslizamiento & Pilón de Azúcar-Tres & 8032218 & 59440058 \\
& & Equis & & \\
67 & Deslizamiento & Laguna Bonilla & 9560428 & 122218848 \\
68 & Deslizamiento & Cimarrones & 9642980 & 138298160 \\
69 & Deslizamiento & Chitaría & 12207972 & 1445139008 \\
\hline
\end{tabular}

de acuerdo a lo propuesto por los métodos Mora \& Vahrson (Mora et al., 1992) y MVM (Mora et al., 2002).

\section{Evaluación del parámetro de la pendiente $\left(S_{P}\right)$}

Este factor valora las condiciones topográficas del terreno, por medio de la creación de un mapa de pendientes del área de estudio, con valores en grados, de acuerdo al método MVM (Mora et al., 2002).

Como se indicó anteriormente, el mapa de pendientes se obtuvo con base en un modelo de elevación digital, a partir de las curvas de nivel a escala 1:25 000, con curvas cada $10 \mathrm{~m}$, estableciendo una rejilla cuadriculada de $10 \times 10 \mathrm{~m}$.

Se utilizó la clasificación de pendientes establecida por van Zuidam (1986), tal como se muestra en el cuadro 2 (Mora et al., 2002). La clasificación comprende pesos relativos (valor del parámetro $\mathrm{S}_{\mathrm{p}}$ ) que van desde 1, para una pendiente baja $\left(0-8^{\circ}\right)$, hasta el valor máximo de 4 , correspondiente con una pendiente muy fuerte $\left(>35^{\circ}\right)$.

Como se observa en la figura 3, en el área de estudio dominan las pendientes fuertes que representan un $35,4 \%$ del área total, seguidas por las pendientes bajas con un $28,9 \%$, las pendientes moderadas con un $26,3 \%$ y por último, las pendientes muy fuertes con un $9,5 \%$.

\section{Evaluación del parámetro de susceptibilidad} litológica $\left(S_{L}\right)$

Este factor valora la influencia de la litología en la formación de deslizamientos. Para el cálculo de este factor, se utilizó el mapa geológico de la figura 4.

En esta investigación se propone la evaluación de este parámetro mediante un enfoque estadístico (que se detallará adelante), a partir de la correspondencia entre las unidades litoestratigráficas y los deslizamientos determinados por fotogeología. Se llevó a cabo una sobreposición espacial (intersección) entre las capas de inventario de deslizamientos y de geología, de la que se obtuvo, para cada litología, el porcentaje de su área que está afectado por deslizamientos, con respecto a

Cuadro 2

Clases de pendientes (van Zuidam, 1986) y valoración del parámetro de la pendiente $\left(\mathrm{S}_{\mathrm{p}}\right)$ (Mora et al., 2002)

\begin{tabular}{ccc}
\hline Clase & Características & $\begin{array}{c}\text { Valor } \\
\text { de } \mathrm{S}_{\mathrm{p}}\end{array}$ \\
\hline Pendiente baja & Pendiente menor a $8^{\circ}$ & 1 \\
Pendiente moderada & $\begin{array}{c}\text { Pendiente entre } 8^{\circ} \text { y } 16^{\circ} \\
\text { Pendiente fuerte }\end{array}$ & 2 \\
& $\begin{array}{c}\text { Pendiente entre } 16^{\circ} \\
\text { y } 35^{\circ}\end{array}$ & 3 \\
Pendiente muy fuerte & Pendiente mayor a 35 & 4 \\
\hline
\end{tabular}




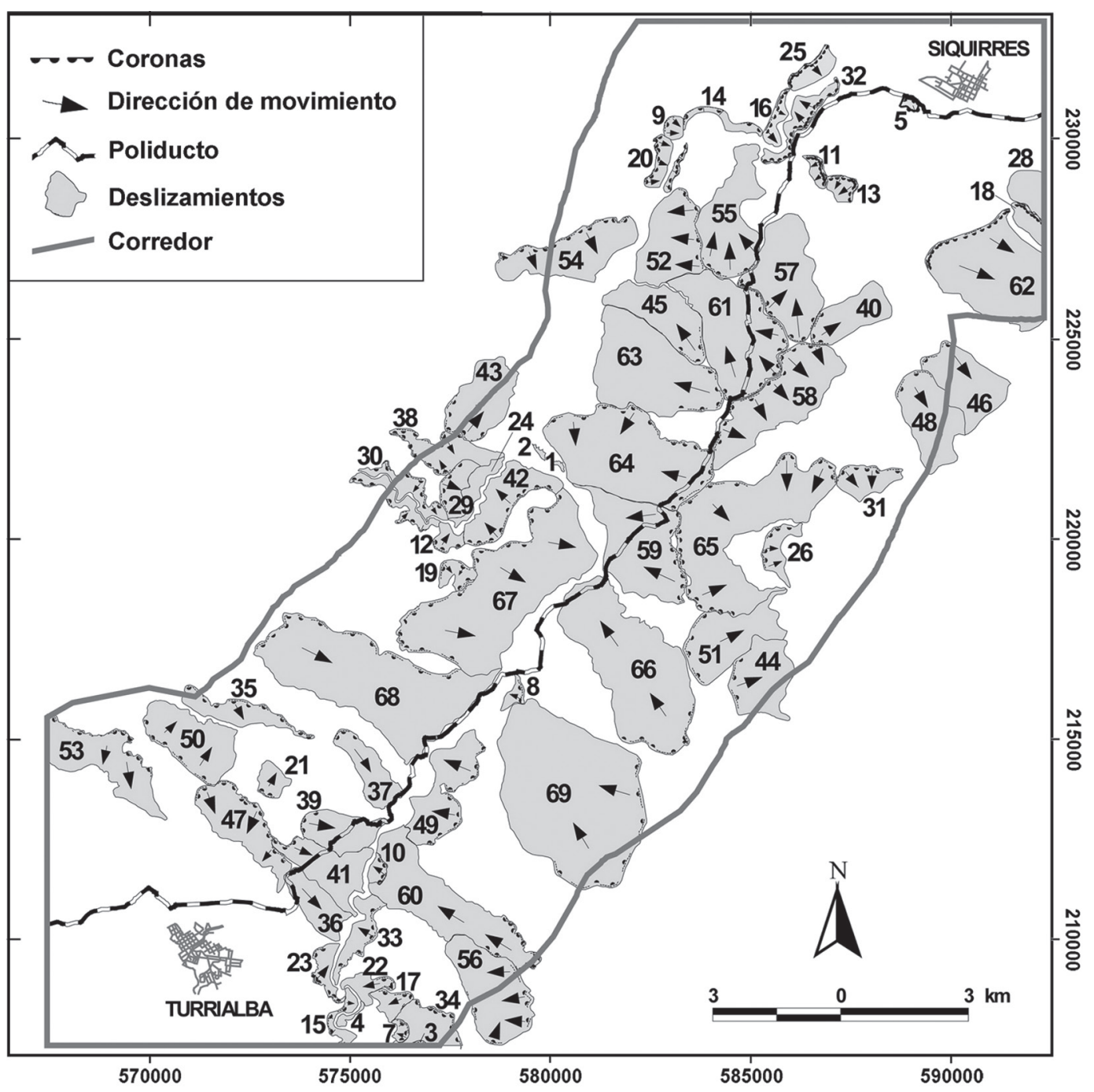

Fig. 2: Mapa inventario de deslizamientos

la extensión total de cada formación; es decir, densidad de deslizamientos por unidad litológica (Cuadro 3).

Los valores de densidad de deslizamientos por unidad litológica se normalizaron estadísticamente utilizando el valor de la densidad para todo el mapa, con el fin de evitar los sesgos producto de las diferencias de área entre una unidad litológica y otra.
$\mathrm{S}_{\mathrm{L}}=$ Densidad de deslizamientos para cada formación (D1) / Densidad de deslizamientos para el área de estudio (D2)

Donde,

D1= Área de deslizamiento para cada formación / Área de cada unidad geológica (4)

D2 = Área total de deslizamiento (147 $\left.\mathrm{km}^{2}\right)$ / Área del corredor $\left(329,9 \mathrm{~km}^{2}\right)$ 


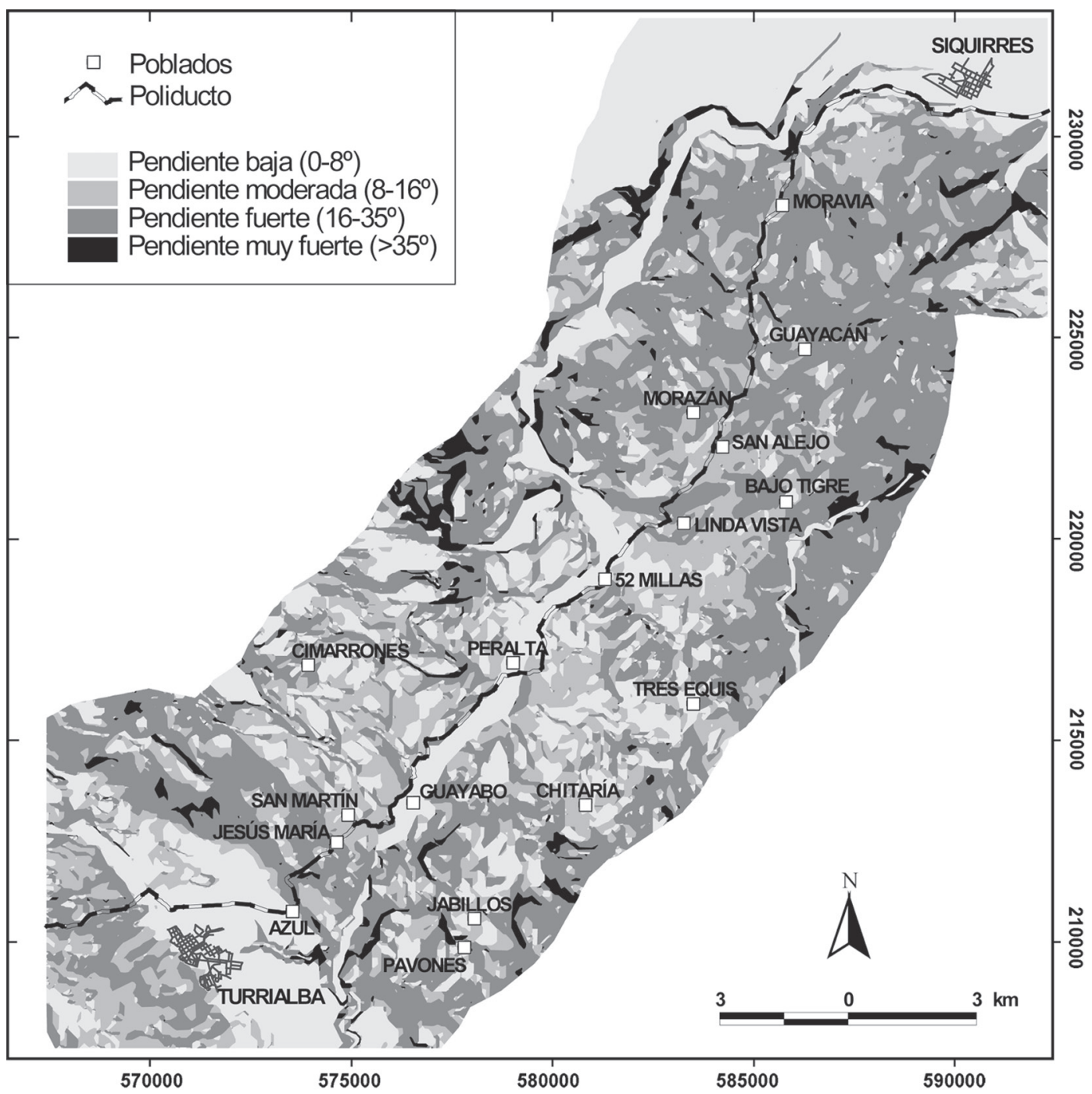

Fig. 3: Mapa de pendientes

El peso asignado a cada unidad litológica (valor del parámetro $\mathrm{S}_{\mathrm{L}}$ ) se obtuvo de la división (ecuación 3) de los valores de densidad de deslizamientos para cada formación (D1, ecuación 4) entre el valor de densidad de deslizamientos para el área de estudio (D2), la cual es una constante que resulta de la razón (ecuación 5) entre los valores totales de área deslizada $\left(147 \mathrm{~km}^{2}\right)$ y área de estudio (329,9 km²) (Cuadro 3).
Como podemos observar en el cuadro 3 , las formaciones más susceptibles de causar deslizamientos son Uscari, Río Banano y Brechas La Unión.

\section{Evaluación del parámetro de humedad del suelo $\left(S_{H}\right)$}

En este caso se recurre a los promedios mensuales de precipitación registrados por las estaciones 


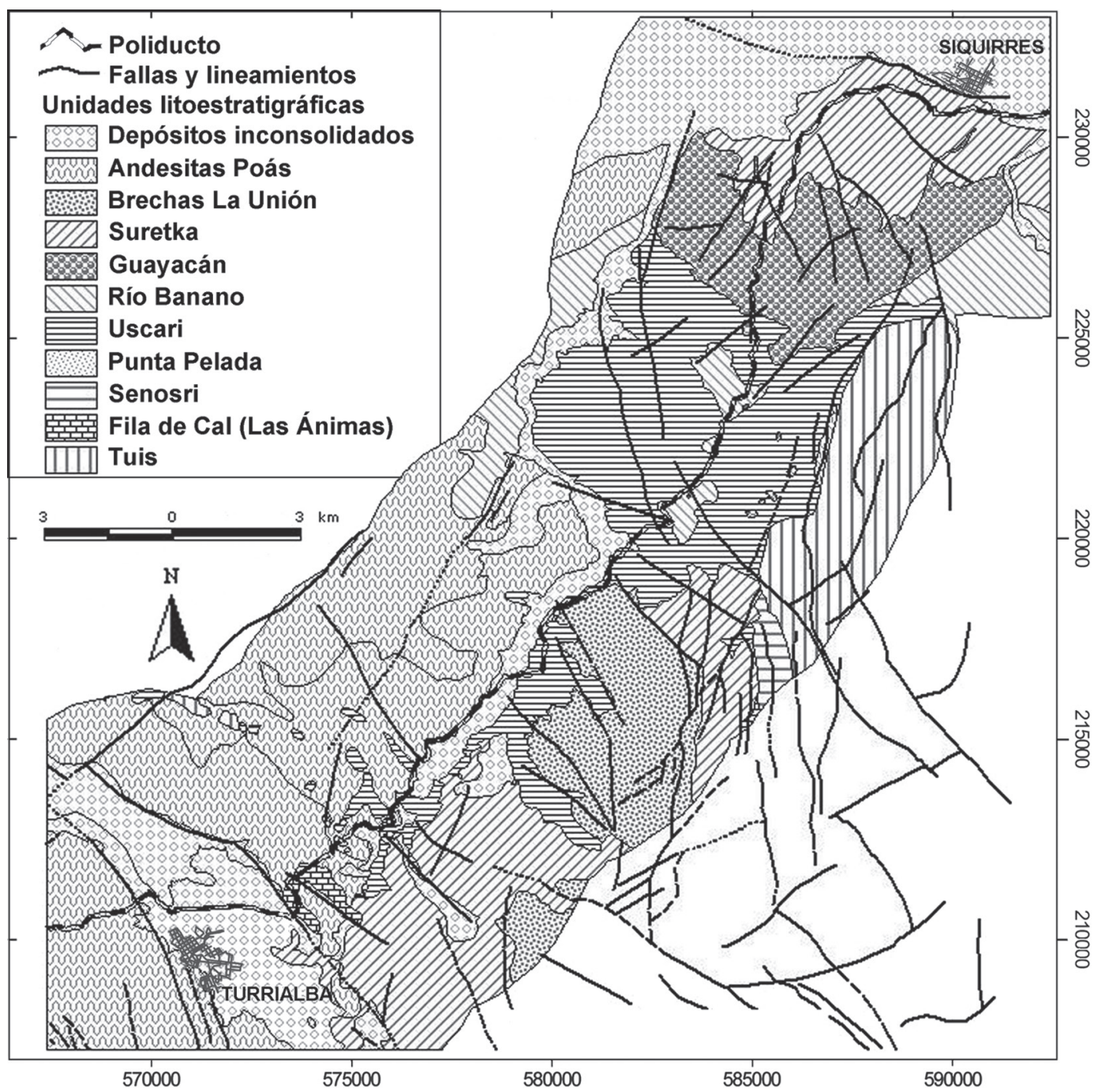

Fig. 4: Mapa geológico del área de estudio (basado en Barboza \& Fernández (1987), Fernández (1987), Chavarría (1996), Pérez (1996), Rojas (1996) y Sibaja (1996))

meteorológicas que el ICE y el IMN tienen distribuidas a lo largo del área de estudio, efectuando con ellos y de acuerdo con lo establecido por la metodología Mora-Vahrson (Mora et al., 1992), un balance hídrico simplificado.

A los promedios mensuales se les asignan los valores del cuadro 4 y se efectúa la suma de estos valores para los doce meses del año, con lo que se obtiene un valor que puede oscilar entren
0 y 24 unidades. El resultado refleja los aspectos relacionados con la saturación y la distribución temporal de humedad en el terreno (Mora et al., 1992).

La valoración del parámetro $\mathrm{S}_{\mathrm{H}}$ se presenta en el cuadro 5. La distribución geográfica y el área de influencia de las estaciones meteorológicas, determinada mediante polígonos de Thiessen, se presentan en la figura 5. 
Cuadro 3

Densidad de deslizamientos para cada formación y valoración del parámetro $\mathrm{S}_{\mathrm{L}}$

\begin{tabular}{ccccc}
\hline Unidades litoestratigráficas & $\begin{array}{c}\text { Área de formación } \\
\left(\mathrm{km}^{2}\right)\end{array}$ & $\begin{array}{c}\text { Área deslizada } \\
\left(\mathrm{km}^{2}\right)\end{array}$ & $\begin{array}{c}\text { Densidad de } \\
\text { Deslizamientos } \\
\text { (ecuación 4) }\end{array}$ & $\begin{array}{c}\text { Valor } \mathrm{S}_{\mathrm{L}} \\
\text { (ecuación 3) }\end{array}$ \\
\hline Dep. Inconsolidados & 63,8 & 8,2 & 0,13 & 0,29 \\
Andesitas Poás & 83,3 & 37,6 & 0,45 & 1,01 \\
Brechas La Unión & 20,4 & 14,2 & 0,70 & 1,57 \\
Suretka & 50,9 & 20,1 & 0,39 & 0,88 \\
Guayacán & 22,3 & 11,3 & 0,51 & 1,14 \\
Río Banano & 15,5 & 11,2 & 0,72 & 1,62 \\
Uscari & 49,3 & 36,1 & 0,73 & 1,64 \\
Punta Pelada & 0,1 & 0 & 0 & 0 \\
Senosri & 1,7 & 0 & 0 & 0 \\
Fila de Cal (Las Ánimas) & 1,6 & 0 & 0 & 0,25 \\
\hline
\end{tabular}

Evaluación del factor de disparo por sismicidad $\left(D_{S}\right)$

La calificación de este factor se realizó con base en la clasificación propuesta por la metodología Mora-Vahrson (Mora et al., 1992) y que se muestra en el cuadro 7.

La evaluación de este parámetro se realizó tomando en consideración los eventos sísmicos presentados en la región durante los últimos 100 años, que han afectado el área de estudio y para los que se ha reportado su intensidad (Rojas, 1991; Barquero \& Peraldo, 1993 y Barquero \& Rojas, 1994).

De acuerdo con lo anterior, la mayor intensidad sísmica reportada para el área de estudio, en un período de 100 años, corresponde con un valor de VII, correspondiente al sismo de Limón de abril de 1991. Por lo tanto, el parámetro de disparo por sismicidad para el área de estudio corresponde con un valor de 5 (calificativo de medio) (Cuadro 7).

\section{Evaluación del factor de disparo por lluvias $\left(D_{L L}\right)$}

Para la evaluación de este factor se utilizó la serie de valores máximos diarios anuales registrados en las estaciones meteorológicas distribuidas en la zona de estudio. Se realizó el cálculo de la precipitación máxima para un período de retorno (T) de 100 años, según el método de Gumbel (Linsley, 1977).

La valoración de este parámetro se realizó según lo propuesto en la metodología MoraVahrson (Mora et al., 1992) y que se muestra en el cuadro 8 .

Los resultados de la calificación del factor de disparo por lluvia, para las áreas de influencia correspondientes a cada una de las estaciones meteorológicas, se presentan en el cuadro 9 y en la figura 6.

Cuadro 4

Valores asignados a los promedios mensuales de lluvia (Mora et al., 1992)

\begin{tabular}{cc}
\hline $\begin{array}{c}\text { Precipitación promedio } \\
(\mathrm{mm} / \mathrm{mes})\end{array}$ & Valor asignado \\
\hline$<125$ & 0 \\
$125-250$ & 1 \\
$>250$ & 2 \\
\hline
\end{tabular}


Cuadro 5

Valoración del parámetro humedad del terreno $\left(\mathrm{S}_{\mathrm{H}}\right)$ (Mora et al., 1992)

\begin{tabular}{ccc}
\hline $\begin{array}{c}\text { Suma de valores asignados a } \\
\text { cada mes }\end{array}$ & Calificativo & Valor $\mathrm{S}_{\mathrm{H}}$ \\
\hline $0-4$ & Muy bajo & 1 \\
$5-9$ & Bajo & 2 \\
$10-14$ & Medio & 3 \\
$15-19$ & Alto & 4 \\
$20-24$ & Muy alto & 5 \\
\hline
\end{tabular}

\section{Resultado del análisis}

Como resultado de la combinación de los parámetros, se obtuvo la zonificación de la susceptibilidad al deslizamiento para el área de estudio, tal como se muestra en la figura 7.

La determinación de esta zonificación se realizó, según lo explicado anteriormente, mediante la aplicación de la ecuación (1) (Mora et al., 2002). Posteriormente, se clasifica en cinco grados de susceptibilidad: Muy baja, Baja, Media, Alta y Muy Alta (Cuadro 10), estableciendo los rangos de valores en cinco intervalos iguales.

Las áreas correspondientes a susceptibilidad baja abarcan la mayor parte del mapa $(37,1 \%)$ y se presentan mayormente en sectores donde afloran las unidades litoestratigráficas Tuis, al sureste del área, Suretka y en algunos sectores de la formación Andesitas Poás. Las áreas correspondientes a susceptibilidad media $(17,8 \%)$

Cuadro 6

Calificación del parámetro $\mathrm{S}_{\mathrm{H}}$ para el área de estudio

\begin{tabular}{cc}
\hline Estación meteorológica & Valor $\mathrm{S}_{\mathrm{H}}$ \\
\hline Guayabo & 4 \\
El Sauce & 5 \\
Pacuar & 5 \\
Siquirres & 5 \\
La Amistad & 5 \\
\hline
\end{tabular}

Cuadro 7

Valoración del parámetro de disparo por sismicidad $\left(\mathrm{D}_{\mathrm{S}}\right)$ (Mora et al., 1992)

\begin{tabular}{ccc}
\hline $\begin{array}{c}\text { Intensidades (Mercalli } \\
\text { Modificada) }\end{array}$ & Calificativo & Valor $\mathrm{D}_{\mathrm{S}}$ \\
\hline III & Leve & 1 \\
IV & Muy bajo & 2 \\
V & Bajo & 3 \\
VI & Moderado & 4 \\
VII & Medio & 5 \\
VIII & Elevado & 6 \\
IX & Fuerte & 7 \\
X & Bastante fuerte & 8 \\
XI & Muy fuerte & 9 \\
XII & Extremadamente & 10 \\
\hline
\end{tabular}

se presentan principalmente en rocas de las formaciones Andesitas Poás, Uscari y Guayacán; mientras que las áreas correspondientes a susceptibilidad alta $(14,2 \%)$ se presentan principalmente en sectores donde afloran las rocas de las formaciones Andesitas Poás, Uscari, Brechas La Unión y Río Banano (Fig.4 y 7).

En lo que respecta a poblados, en la figura 7 puede observarse que Morazán, Guayacán, San Alejo, Bajo Tigre y Linda Vista se encuentran en o muy cerca de zonas de susceptibilidad alta. No existen poblados localizados sobre áreas de susceptibilidad muy alta.

\section{Cuadro 8}

Valoración del factor de disparo por lluvias $\left(\mathrm{D}_{\mathrm{LL}}\right)$ (Mora et al., 1992)

\begin{tabular}{ccc}
\hline $\begin{array}{c}\text { Lluvias máximas T=100 años } \\
(\mathrm{mm})\end{array}$ & Calificativo & Valor DLL \\
\hline$<100$ & Muy bajo & 1 \\
$100-200$ & Bajo & 2 \\
$201-300$ & Medio & 3 \\
$301-400$ & Alto & 4 \\
$>400$ & Muy alto & 5 \\
\hline
\end{tabular}




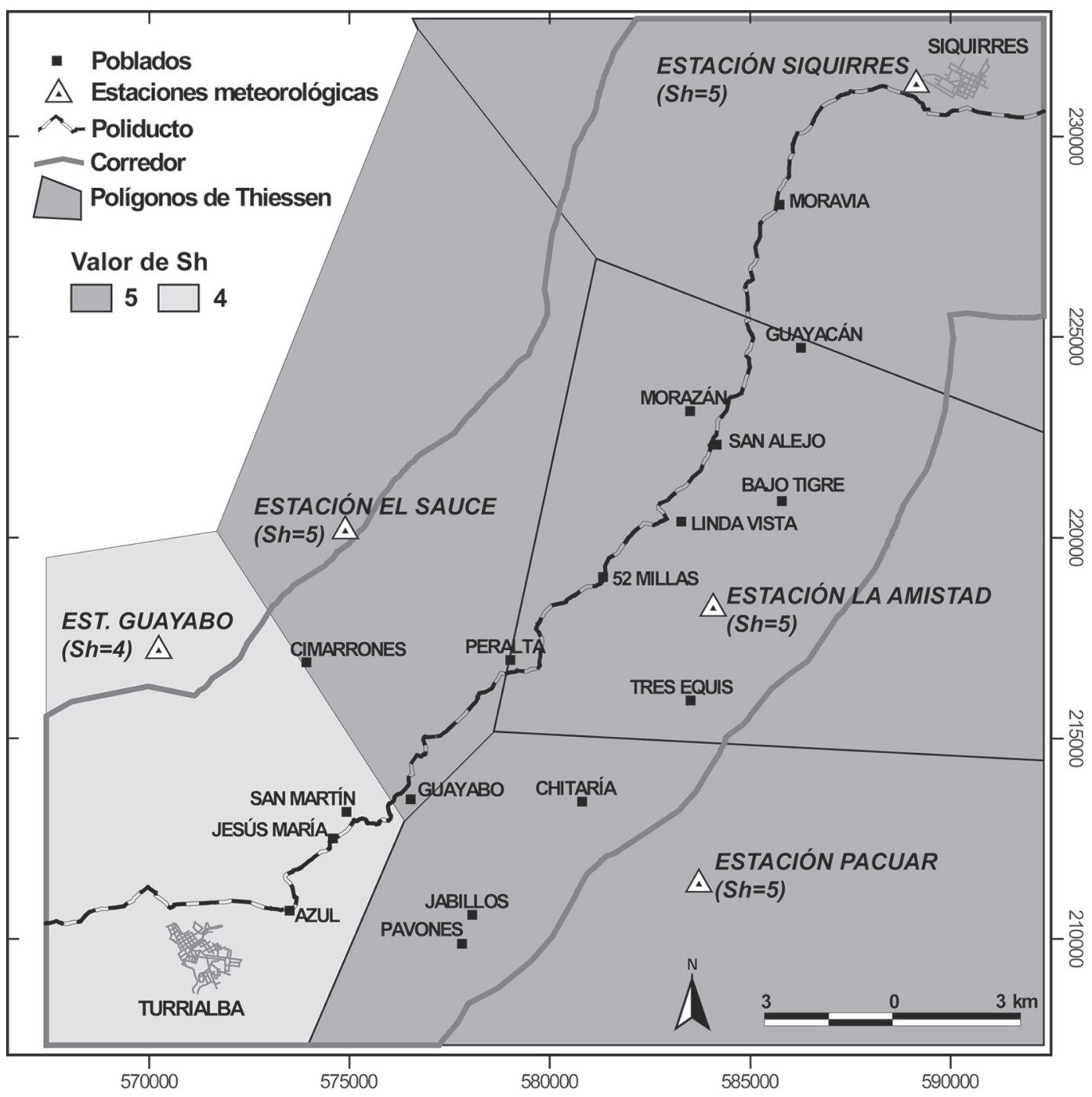

Fig. 5: Área de influencia de las estaciones meteorológicas (Polígonos de Thiessen) y valoración del parámetro SH

\section{Evaluación de la metodología utilizada}

La zonificación permitió realizar un reconocimiento preliminar de las áreas con diferentes grados de susceptibilidad a generar deslizamientos; permitió además definir zonas críticas, que posteriormente han de ser objeto de estudios detallados en el campo.
Como se indicó en el apartado de metodología, la evaluación del método utilizado se basó principalmente en la determinación del grado de coincidencia entre las áreas de deslizamientos y las áreas para cada clase de susceptibilidad (Fig. 8).

A partir de esta intersección, se determinó que el $49,1 \%\left(72,1 \mathrm{~km}^{2}\right)$ de las áreas deslizadas presentan un grado de susceptibilidad media a muy 
Cuadro 9

Calificación del factor por lluvia para el área de estudio

\begin{tabular}{ccc}
\hline Nombre & $\begin{array}{c}\text { Lluvia máxima T }=100 \\
\text { años }(\mathrm{mm})\end{array}$ & Valor $\mathrm{D}_{\mathrm{LL}}$ \\
\hline GUAYABO & 334,8 & 4 \\
EL SAUCE & 466,1 & 5 \\
PACUAR & 391,8 & 4 \\
SIQUIRRES & 398,7 & 4 \\
LAAMISTAD & 423,7 & 5 \\
\hline
\end{tabular}

alta (Cuadro 11). El 50,9\% $\left(74,8 \mathrm{~km}^{2}\right)$ restante corresponde con áreas de susceptibilidad baja y muy baja, lo que se asocia con sectores donde la pendiente del terreno es baja $\left(0-8^{\circ}\right)$ a moderada (8-16 $)$ (compárese con Fig. 3).

Las áreas de deslizamientos coinciden mayormente con áreas de susceptibilidad baja $(35,5 \%)$, mientras que casi la mitad de ellas $(48,4 \%)$ corresponde con áreas de susceptibilidad media y alta. Las pendientes ejercen un control importante en la clasificación de las áreas de susceptibilidad muy baja, lo que se evidencia con que el 57,4\% de estas áreas presentan pendientes bajas.

Como se indicó anteriormente, dentro de las áreas mapeadas como deslizamientos, se incluyeron tanto zonas activas como inactivas. De igual manera, no se hizo diferenciación entre las coronas de los deslizamientos y las zonas de depósitos. Observaciones de campo e interpretación fotogeológica permiten asegurar que, muchas de

Cuadro 10

Clasificación de la susceptibilidad al deslizamiento

\begin{tabular}{ccc}
\hline $\begin{array}{c}\text { Rango de } \\
\text { valores }\end{array}$ & Susceptibilidad & $\begin{array}{c}\text { \% del área de } \\
\text { estudio }\end{array}$ \\
\hline $0-52$ & Muy Baja & 30,3 \\
$52-105$ & Baja & 37,1 \\
$105-157$ & Media & 17,8 \\
$157-210$ & Alta & 14,2 \\
$210-262$ & Muy Alta & 0,5 \\
\hline
\end{tabular}

Cuadro 11

Áreas de deslizamientos según clases de susceptibilidad

\begin{tabular}{ccc}
\hline Susceptibilidad & $\begin{array}{c}\text { Área deslizada } \\
\left(\mathrm{km}^{2}\right)\end{array}$ & Porcentaje \\
\hline Muy baja & 22,7 & 15,5 \\
Baja & 52,1 & 35,5 \\
Media & 36,5 & 24,8 \\
Alta & 34,7 & 23,6 \\
Muy alta & 0,9 & 0,6 \\
Total & 147,0 & 100,0 \\
\hline
\end{tabular}

las áreas mapeadas como deslizamientos y zonificadas como de susceptibilidad media, baja o muy baja por el método aplicado, podrían estar relacionadas con deslizamientos antiguos y zonas de depositación, las cuales presentan frecuentemente pendientes bajas, por lo que no son detectadas como áreas problemáticas en lo que respecta a procesos de remoción en masa.

Dados los resultados obtenidos en el análisis utilizando esta metodología, se concluye que existe una alta confiabilidad en la misma para la obtención del mapa de susceptibilidad al deslizamiento.

\section{CONCLUSIONES}

a) El $32,5 \%\left(107,3 \mathrm{~km}^{2}\right)$ del área del corredor analizado, comprende áreas clasificadas de susceptibilidad media, alta y muy alta. Las áreas que presentan una susceptibilidad muy baja corresponden principalmente con los sectores de los valles de los Río Reventazón y Turrialba y la parte norte del área de estudio, donde afloran los Depósitos Inconsolidados y en algunos sectores donde afloran las rocas de las formaciones Andesitas Poás y Suretka.

b) El análisis fotogeológico permitió determinar las principales áreas de deslizamientos en 


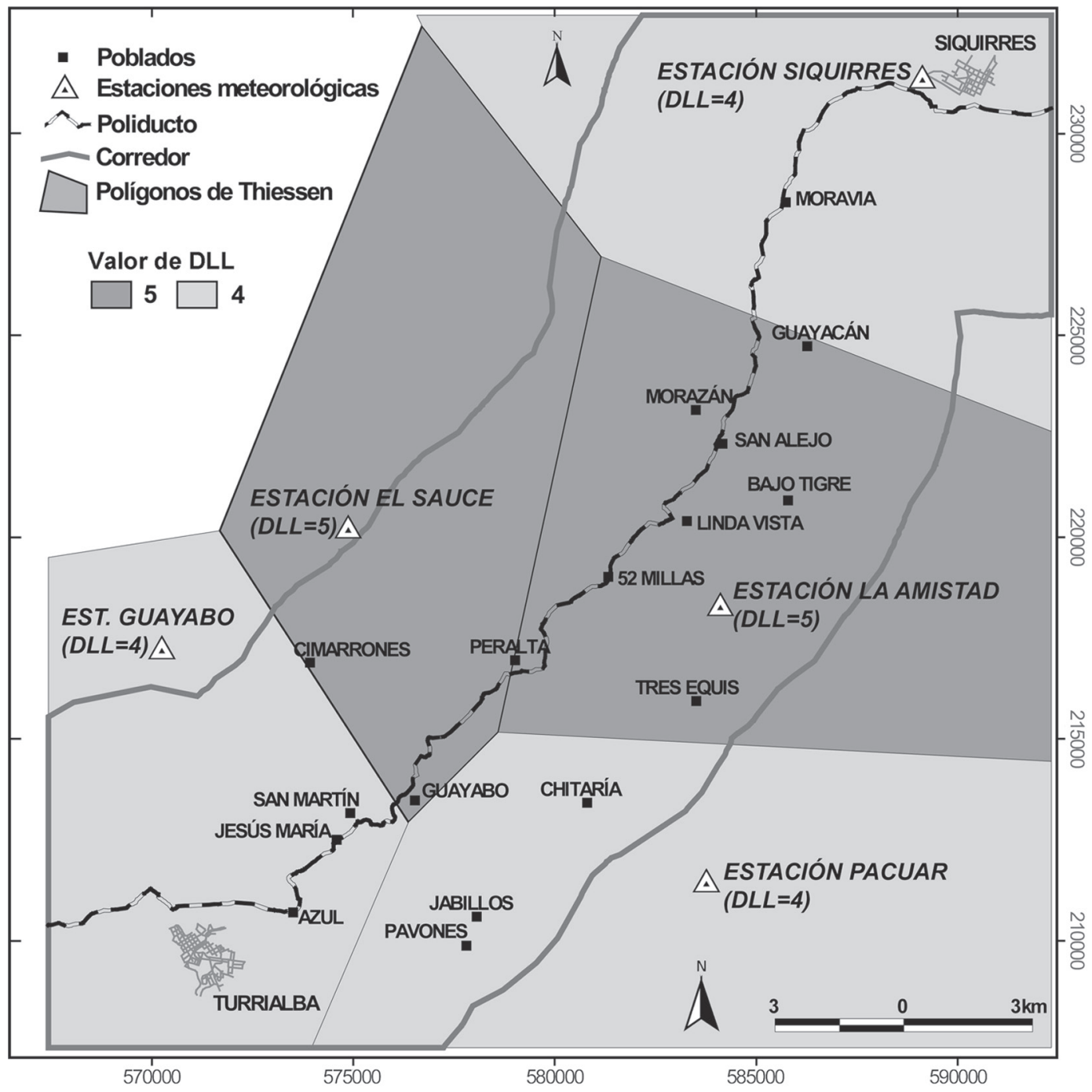

Fig. 6: Área de influencia de las estaciones meteorológicas (Polígonos de Thiessen) y valoración del parámetro DLL

la zona del corredor del poliducto. Este mapa inventario incluye 69 deslizamientos antiguos y activos; sin embargo, el grado de actividad para cada uno de los deslizamientos en particular no fue definido, como tampoco el tipo de movimiento asociado. c) Los deslizamientos comprenden un área de $147 \mathrm{~km}^{2}$ de los $330 \mathrm{~km}^{2}$ que abarca el corredor, representando un 44,6\% del área total.

d) El mapa de zonificación de susceptibilidad al deslizamiento, obtenido con base en la evaluación de factores morfodinámicos para el 


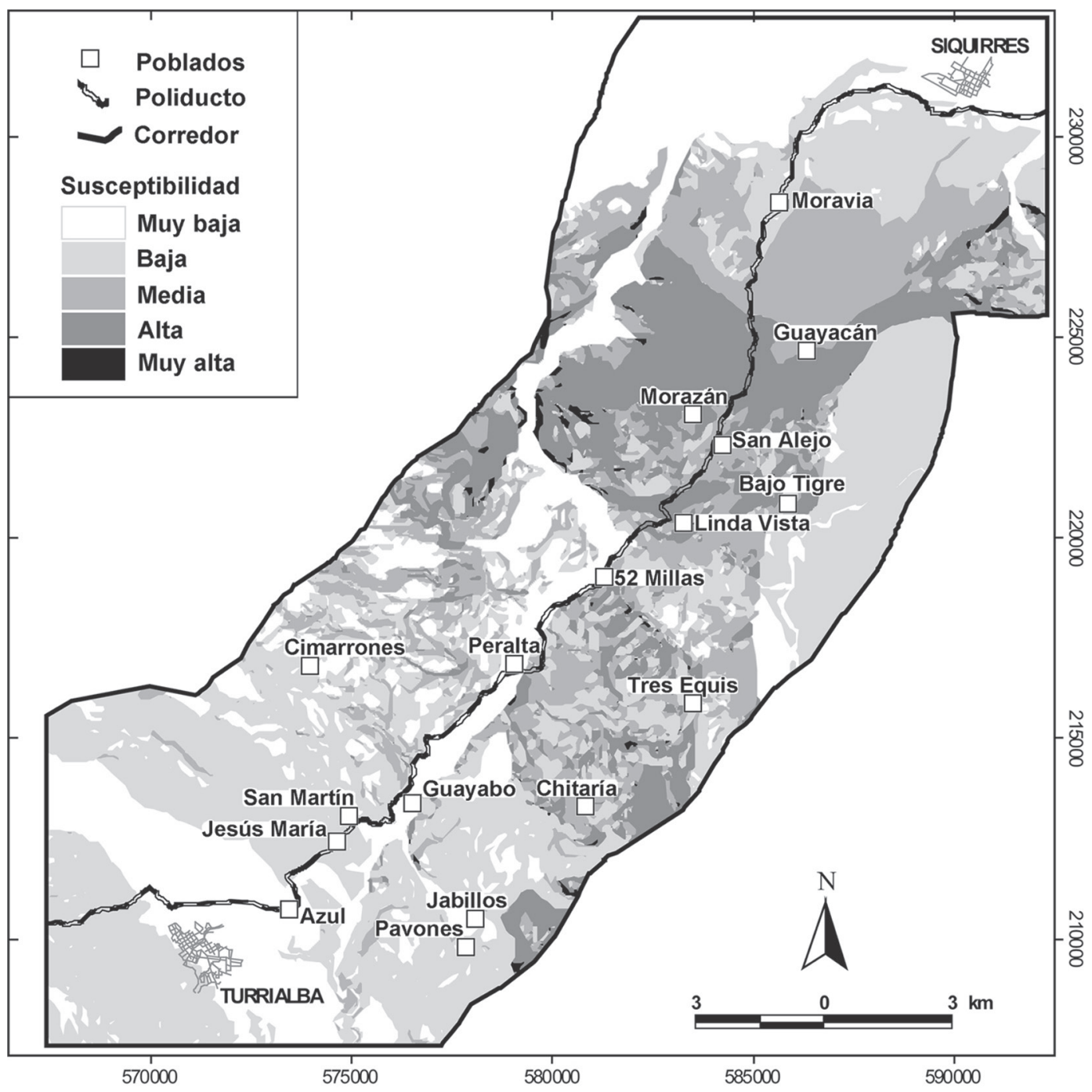

Fig. 7: Mapa de susceptibilidad al deslizamiento

corredor del poliducto, permitió determinar que un $32,5 \%\left(107,3 \mathrm{~km}^{2}\right)$ del área del corredor comprende áreas clasificadas de susceptibilidad media, alta y muy alta.

e) Como parte del proceso de evaluación de la metodología empleada, se determinó que el $49 \%\left(72,1 \mathrm{~km}^{2}\right)$ de las áreas deslizadas presentan un grado de susceptibilidad media a muy alta. El 51\% restante $\left(74,9 \mathrm{~km}^{2}\right)$, corresponde con áreas de susceptibilidad baja y muy baja. f) El 70,2\% de las áreas de susceptibilidad muy baja y el 51,9\% de susceptibilidad baja, corresponden con los sectores de los deslizamientos que presentan una pendiente baja $\left(0-8^{\circ}\right)$ y moderada $\left(8-16^{\circ}\right)$. La metodología utilizada en esta investigación permitió determinar, de forma confiable, las áreas con diferente potencial para el desarrollo de deslizamientos. 


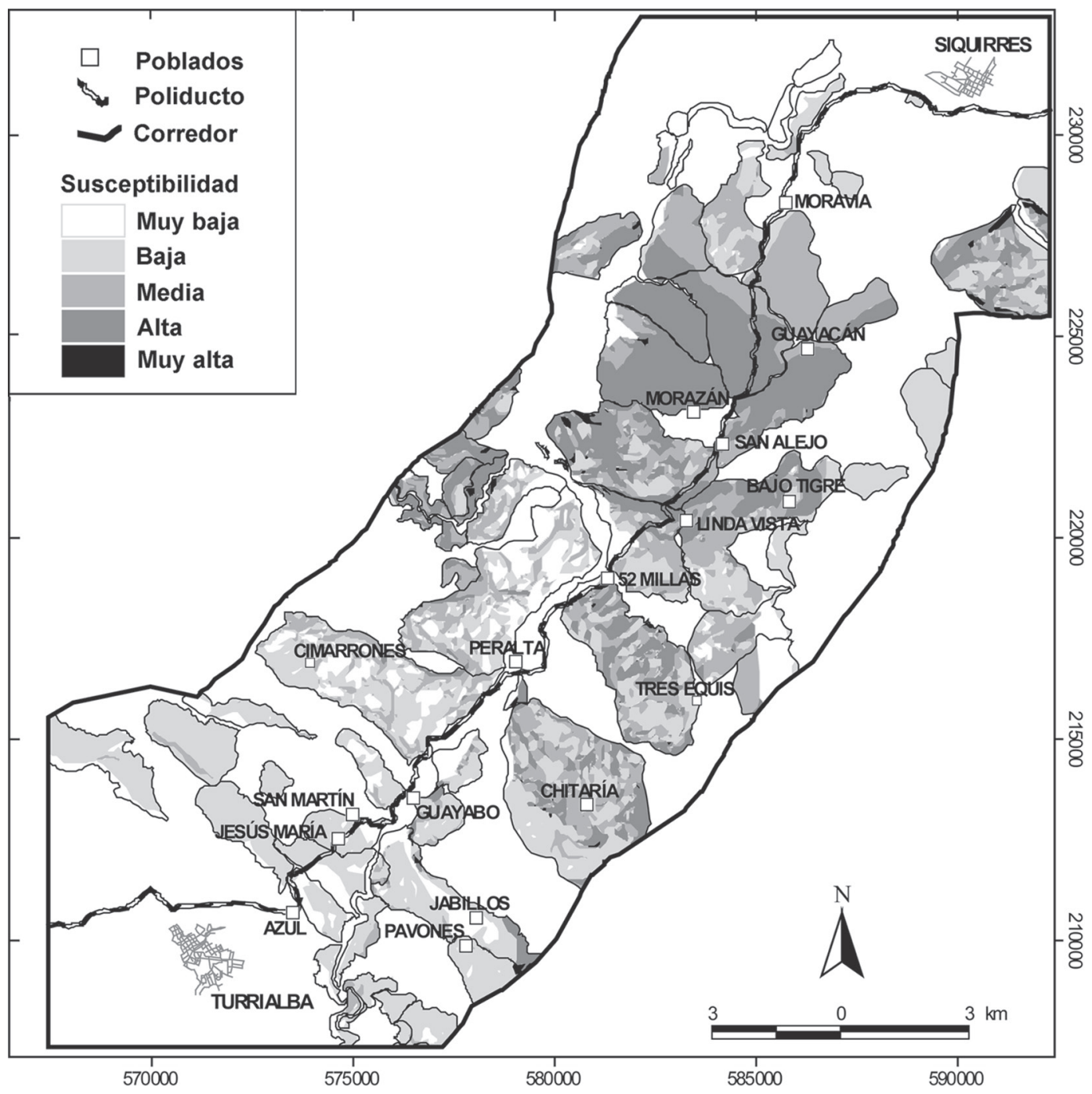

Fig. 8: Mapa de intersección de las capas de inventario de deslizamientos y susceptibilidad al deslizamiento

\section{RECOMENDACIONES}

El inventario de deslizamientos incluye deslizamientos antiguos y activos; sin embargo, el grado de actividad para cada uno de los deslizamientos en particular no fue definido. Por lo tanto, se recomienda realizar un reconocimiento de campo para verificar las áreas actualmente activas que representan una amenaza potencial para las comunidades.
De igual manera, se recomienda incorporar la variable de susceptibilidad geomorfológica, tal y como proponen autores como Camacho et al. (2004) y Bonilla (2006), con el fin de incorporar al análisis, información espacial relacionada con la ubicación de deslizamientos activos, inactivos, sus coronas, zonas de depositación, etc. De este modo se solventa en gran medida, el problema de que zonas de deslizamiento sean 
consideradas por el método como áreas poco susceptibles a la inestabilidad de laderas.

Se recomienda a las autoridades correspondientes, planificar el desarrollo urbano y de infraestructura en general, considerando los sectores de mayor susceptibilidad al deslizamiento y las áreas de deslizamientos presentadas en el mapa.

El mapa inventario de deslizamientos, generado con base en fotografías aéreas, permitió evaluar el factor litológico de manera adecuada. Por lo tanto, se recomienda considerar el reconocimiento fotogeológico como mecanismo para la evaluación de este factor.

\section{AGRADECIMIENTOS}

La presente investigación es un extracto de la tesis del geólogo Gustavo Segura Cortés, para optar por el título de Licenciado en Geología de la Escuela Centroamericana de Geología de la Universidad de Costa Rica (Segura, 2009). Además, se desarrolló en el marco del Proyecto de Investigación $\mathrm{N}^{\circ}$ 830-A8-070, titulado "Zonificación de la inestabilidad de laderas mediante Sistemas de Información Geográfica y percepción remota", del Centro de Investigaciones en Ciencias Geológicas.

\section{REFERENCIAS}

BARBOZA, G. \& FERNÁNDEZ, J. A., 1987: Mapa geológico del área norte de la cuenca Limón Sur.- Escala 1:50 000, RECOPE, San José.

BARQUERO, R. \& PERALDO, G., 1993: El temblor de Pejibaye de Turrialba del 10 de julio de 1993: aspectos sismológicos, geotectónicos y geotécnicos.- 46 págs. RSN (ICE-UCR), San José [Inf. Interno].

BARQUERO, R. \& ROJAS, W., 1994: Catálogo de mapas de isosistas de temblores y terremotos importantes de Costa Rica.- 58 págs. RSN (ICE-UCR), San José [Inf. Interno].
BONILLA, E., 2006: Estudio diagnóstico de amenazas asociadas a la geodinámica externa de la parte media de la cuenca del río Limón, Cantón de Buenos Aires, Puntarenas.- 123 págs. Universidad de Costa Rica, San José. [Tesis Lic.].

CAMACHO, D., CHAVES, J. \& MURILLO, D., 2004: Diagnóstico de la susceptibilidad al deslizamiento e inundación, análisis del contexto sísmico y reconocimiento de peligros volcánicos para el cantón de Montes de Oca: una contribución al plan regulados del municipio.- 106 págs. Universidad de Costa Rica, San José. [Tesis Lic.].

CARRARA, A., CARDINALI, M., GUZZETTI, F. \& REICHENBACH, P., 1995: GIS technology in mapping landslide hazard.- En: CARRARA, A. \& GUZZETTI, F. (eds.): Geographical Information Systems in assessing natural hazards.- 353 págs. Kluwer Academic Publishers, Holanda.

CHAVARRÍA, L., 1996: Estudio geológico geotécnico del corredor Turrialba-Siquirres, sección Río Torito-Laguna Bonilla poliducto de Recope, Provincia de Cartago, Costa Rica.- 75 págs. Univ. de Costa Rica, San José [Inf. Campaña Geol.].

FERNÁNDEZ, J.A., 1987: Geología de la hoja topográfica Tucurrique 1:50 000 IGNCR, 3445I.- 205 págs. Univ. de Costa Rica, San José [Tesis Lic.].

IGN, 1967: Hoja topográfica Bonilla.- Escala 1:50 000, Instituto Geográfico Nacional, San José.

IGN, 1981: Hoja topográfica Tucurrique.- Escala 1:50 000, Instituto Geográfico Nacional, San José.

LINKIMER, L. \& AGUILAR, T., 2000: Estratigrafía Sedimentaria.- En: DENYER, P. KUSSMAUL, S. (eds): Geología de Costa Rica.- 515 págs. Ed. Tecnológica de Costa Rica, Cartago. 
LINSLEY, R.K., KOHLER, M.A. \& PAULHUS, J.L., 1977: Hidrología para ingenieros.386 págs. Ed. McGraw-Hill, México.

MORA, R., CHÁVEZ, J. \& VÁSQUEZ, M., 2002: Zonificación de la susceptibilidad al deslizamiento: Resultados obtenidos para la Península de Papagayo mediante la modificación del método Mora \& Vahrson (Mora et al., 1992).- Memoria del tercer curso internacional sobre microzonificación y su aplicación en la mitigación de desastres. Lima, Perú. 38-46.

MORA, R., MORA, S. \& VAHRSON, W., 1992: Macrozonificación de la amenaza de deslizamientos y resultados obtenidos en el área del valle central de Costa Rica.- Escala 1:286 000, CEPREDENAC, San José de Costa Rica.

PERALDO, G. \& ROJAS, E., 1998: La deslizable historia del ferrocarril al Caribe de Costa Rica.- Anuario de Estudios Centroamericanos, 24(1-2): 97-128.

PERAZZO, E., CERVANTES, J.F. \& MORA, S., 1994: Proyecto hidroeléctrico Angostura: análisis de la estabilidad del deslizamiento de Piedras de Fuego, evaluación de la amenaza.121 págs. ICE, San José [Inf. Interno].

PÉREZ, W., 1996: Estudio geológico y de amenazas naturales Corredor Turrialba-Siquirres, poliducto de Recope, sector Laguna Bonilla-Guayacán.- 71 págs. Univ. de Costa Rica, San José [Inf. Campaña Geol.].

ROJAS, M., 1996: Estudio geológico-geotécnico del corredor Turrialba-Siquirres, sección Alto Guayacán-Siquirres del Poliducto Recope.- 67 págs. Univ. de Costa Rica, San José [Inf. Campaña Geol.].

ROJAS, W., 1991: El terremoto del 22 de abril de 1991 en la región Caribe y la sismicidad asociada en el mes de abril, 1991, Costa Rica.- 57 págs. RSN (ICE-UCR), San José [Inf. Interno].

SÁENZ, L.F., 1985: Estudio geofísico para la factibilidad del proyecto hidroeléctrico Angostura-Turrialba, Costa Rica.- 74 págs. Univ. de Costa Rica, San José [Tesis Lic.].

SEGURA, G., 2009: Análisis mediante aplicaciones SIG de la susceptibilidad al deslizamiento en el corredor Siquirres-Turrialba como factor de riesgo del poliducto de RECOPE.- 74 págs. Univ. de Costa Rica, San José [Tesis Lic.].

SIBAJA, G.E., 1996: Estudio geológico-geotécnico del corredor Turrialba-Siquirres, poliducto de Recope, sección Turrialba-Río Torito Estudio.- 88 págs. Univ. de Costa Rica, San José [Inf. Campaña Geol.].

VAN WESTEN, C.J. \& SOETERS, R., 2000: Remote Sensing and Geographic Information Systems for Natural Disaster Management.- En: ROY, P.S., VAN WESTEN, C.J., JHA, V.K., LAKHERA, R.C. \& CHAMPATI RAY, P.K. (eds): Natural Disasters and their Mitigation. A Remote Sensing and GIS Perspective.Indian Institute of Remote Sensing, National Remote Sensing Agency, India: 31-76.

VAN ZUIDAM, R. A., 1986: Aerial photointerpretation in terrain analysis and geomorphologic mapping.- 442 págs. Smits Publishers, The Hague.

VARNES, D.J., 1978: Slope movement types and processes.- En: SCHUSTER, R.L. \& KRIZEK, R.J. (eds): Landslides - Analysis and control. National Research Council, Transportation research board, Washington D. C., Special Report 176: 11-33. 